\title{
Cohort profile: King's Health Partners bladder cancer biobank
}

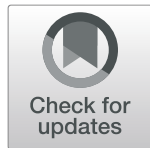

\author{
Pinky Kotecha ${ }^{1}$, Charlotte L. Moss ${ }^{1 *}$ (D), Deborah Enting ${ }^{2}$, Cheryl Gillett ${ }^{3}$, Magdalene Joseph ${ }^{1}$, Debra Josephs ${ }^{2}$, \\ Sarah Rudman², Simon Hughes², Fidelma Cahill', Harriet Wylie', Anna Haire', James Rosekilly ${ }^{3}$, \\ Muhammad Shamin Khan ${ }^{4}$, Rajesh Nair ${ }^{3}$, Ramesh Thurairaja ${ }^{4}$, Sachin Malde ${ }^{4}$ and Mieke Van Hemelrijck
}

\begin{abstract}
Background: Bladder cancer (BC) is the 9th most common cancer worldwide, but little progress has been made in improving patient outcomes over the last 25 years. The King's Health Partners (KHP) BC biobank was established to study unanswered, clinically relevant BC research questions.

Donors are recruited from the Urology or Oncology departments of Guy's Hospital (UK) and can be approached for consent at any point during their treatment pathway.

At present, patients with bladder cancer are approached to provide their consent to provide blood, urine and bladder tissue. They also give access to medical records and linkage of relevant clinical and pathological data across the course of their disease. Between June 2017 and June 2019, 531 out of 997 BC patients (53.3\%) gave consent to donate samples and data to the Biobank. During this period, the Biobank collected fresh frozen tumour samples from 90/178 surgical procedures (of which 73 were biopsies) and had access to fixed, paraffin embedded samples from all patients who gave consent. Blood and urine samples have been collected from 38 patients, all of which were processed into component derivatives within 1 to $2 \mathrm{~h}$ of collection. This equates to 193 peripheral blood mononuclear cell vials; 238 plasma vials, 224 serum vials, 414 urine supernatant vials and 104 urine cell pellets. This biobank population is demographically and clinically representative of the KHP catchment area.

Conclusion: The King's Health Partners BC Biobank has assembled a rich data and tissue repository which is clinically and demographically representative of the local South East London BC population, making it a valuable resource for future BC research.
\end{abstract}

Keywords: Bladder cancer, Real world evidence, Biobank

\section{Background}

Bladder cancer is the 9th most common cancer worldwide with around 430,000 new cases diagnosed in 2012 [1]. Nevertheless, outcomes in bladder cancer have remained largely unchanged over the last 25 years and much remains unknown about this complex disease, especially with regard to disease aetiology and progression

\footnotetext{
* Correspondence: charlotte.moss@kcl.ac.uk

${ }^{1}$ Translational Oncology \& Urology Research (TOUR), School of Cancer and Pharmaceutical Sciences, King's College London, Guy's Hospital, 3rd Floor Bermondsey Wing, London SE1 9RT, UK

Full list of author information is available at the end of the article
}

[2]. Urological biobanking can therefore provide a valuable resource to answer a number of clinically relevant research questions [2], spurring translation into practical applications and ultimately leading to improvements in public health and healthcare.

King's Health Partners (KHP) is an Academic Health Science Centre bringing together King's College London, Guy's and St Thomas' NHS Foundation Trust (GSTT), King's College Hospital NHS Foundation Trust and the South London and Maudsley NHS Foundation Trust, as shown in Fig. 1 [3]. 


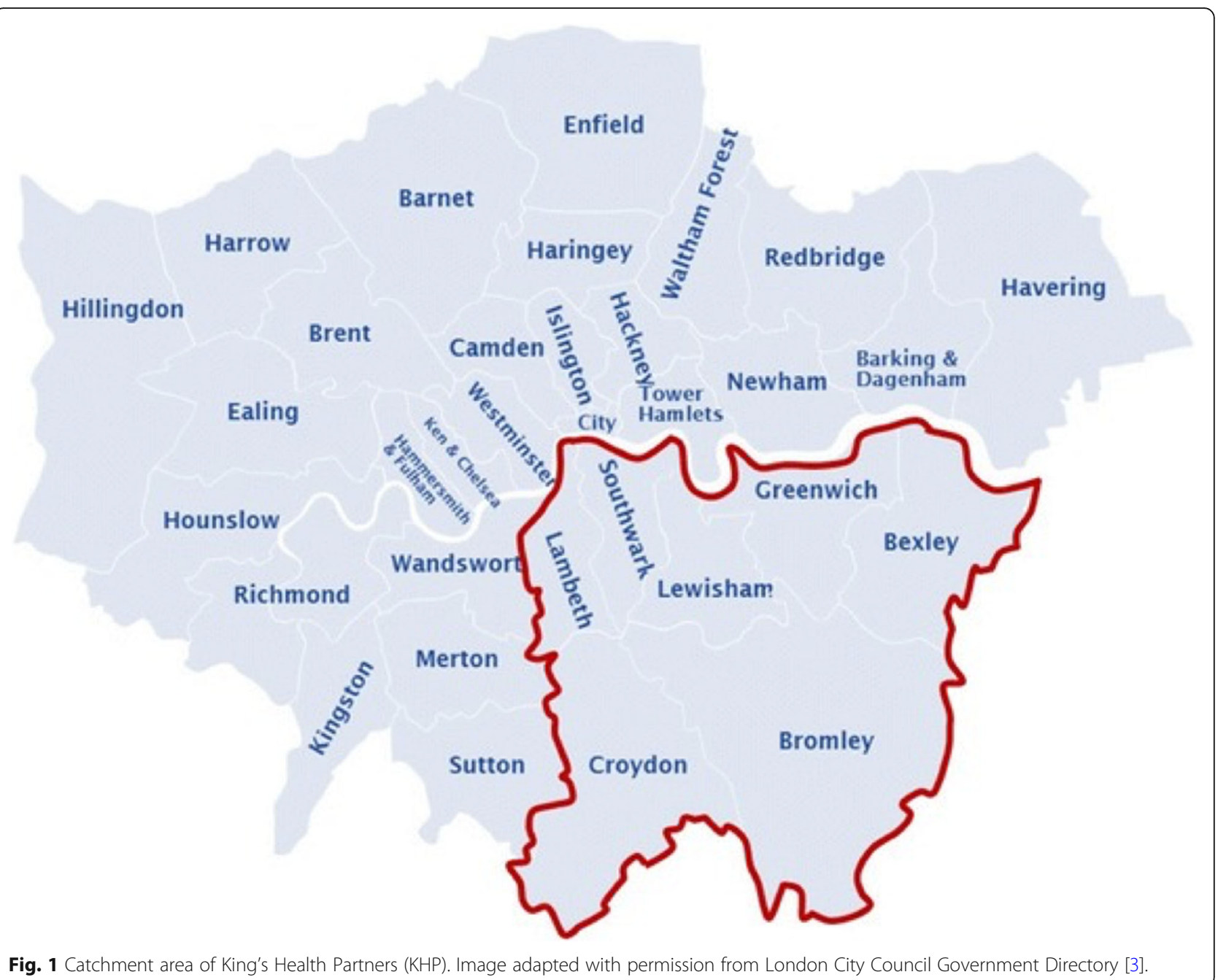

The KHP Bladder Cancer Biobank was established in April 2017 as part of the overarching KHP Cancer Biobank. Bladder cancer patients are recruited from the Urology and Oncology departments of Guy's Hospital and provide their consent to donate blood, urine, tissue surplus to diagnostic requirements and extra tissue samples just for the Biobank. Patients may be approached to give consent at any point of their treatment journey, therefore allowing the Biobank to access residual material from an earlier diagnosis. Thus, although patients only started giving their consent from June 2017, the Biobank has samples collected both before and after this date. Clinical data relevant to bladder cancer can be linked to the biobank samples and data across the entire patient treatment journey. The resource encourages translational research and provides a bridge to patient care. The Biobank samples can be used to exhaustion, creating new research data that can be re-used by investigators. In addition, there is a potential for patients of the KHP Bladder Cancer Biobank to be linked to our ongoing Trials within Cohort Study (TWiCs), the Graham Roberts Study [4], which provides a unique opportunity to answer a wide variety of research questions of a clinical, mechanistic, as well as supportive care nature in the area of bladder cancer.

The KHP Cancer Biobank is licenced by the Human Tissue Authority (reference number 12121) and is a NHS Research Ethics Committee approved Tissue Bank with generic ethical approval to supply bioresources (reference number 18/EE/0025) [5].

Because of our catchment area (Fig. 1), KHP covers a wide range of ethnic and socioeconomic backgrounds, hence providing a unique and valuable resource.

\section{Construction and content}

A recent audit of the KHP Bladder Cancer Biobank highlighted that between April 2017-June 2019, 1089 patients were seen in a bladder clinic, with 997 subsequently diagnosed with bladder cancer. 552 patients gave their consent and following exclusion due to miscoding, 
531 (53.3\%) were included in the KHP Bladder Cancer Biobank. Recruitment for the biobank is ongoing (Fig. 2).

The patients who gave consent to the KHP Bladder Cancer Biobank can be considered representative of the total KHP bladder cancer population attending clinics at GSTT, therefore making the biobank an ideal platform to explore the different features of bladder cancer. The mean age of the overall bladder cancer population seen at GSTT between April 2017 and June 2019 was 70.9 years (SD: 11.6), as compared to 71.03 years (SD: 10.55 ) for the biobanked population (Table 1). In addition, we observed similarities in sex distribution $(78.9 \%$ males in the consented population vs $74.9 \%$ in the total population) and tumour grade distribution (e.g. 62.0\% Grade 3 in the consented population vs $59.6 \%$ in the total population) (Table 2).

\section{Tissue/ biospecimen repository}

The KHP Bladder Cancer biobank includes fixed, paraffin embedded samples that are surplus to diagnostic requirement from all patients who gave consent and underwent a surgical procedure. Where possible, the Biobank collects fresh tumour and normal tissue from both resections and at biopsy. The Biobank has specialist Advanced Practitioners who review all potential specimens for suitability and are trained to partially dissect a fresh specimen and take samples for research but without impacting on the diagnostic integrity. Fresh frozen tissue is validated and stored at $-80^{\circ} \mathrm{C}$ until required. All procedures are fully documented, and ischaemic times recorded, generating a specific sample-related data that can be provided to users of the resource.

During the 2-year audit period, the Biobank has collected fresh frozen tumour samples from 90/178 surgical procedures (of which 73 were a biopsy). Fixed, paraffinembedded blocks are available from all 178 surgical procedures and if the Biobank so wished, it could request access to any tissue samples taken from the 531 patients who gave their consent.

Matched whole blood samples are also collected, from which a number of derivates are obtained including peripheral blood mononuclear cells (PBMC), plasma, serum and red blood cells. The derivatives are aliquoted, frozen and stored at $-80{ }^{\circ} \mathrm{C}$. From urine samples, derivatives of urine supernatant and urine cell pellets are also generated and similarly stored. Similar to the tissue collection, data is recorded on processing procedures and times, number of derivatives and volume per aliquot.

Both blood and urine samples have been collected for 38 patients, which have been processed into 193 peripheral blood mononuclear cell vials; 238 plasma vials, 224 serum vials, 414 urine supernatant vials and 104 urine cell pellets.

A unique biobank identifier is automatically assigned to each new sample, which links to the donor. A second Research ID number is also created at the same time, which is used by researchers. Hence, this double anonymisation system provides the biobank with inbuilt security processes which protect patient data. Moreover, this ensures the collection of comprehensive data profiles as pathological data is linked to clinical patient data.
KHP BCaBB April 2017-June 2019

531 Bladder Ca patients

Tissue
90 Fresh Frozen Historic Formalin-Fixed Paraffin-Embedded 224 Serum 238 Plasma 193 Peripheral Blood Mononuclear Cells 414 urine supernatant vials 104 urine cell pellets.

\section{ongoing}


Table 1 Demographic information of KHP Bladder Cancer Biobank from April 2017-June 2019

\begin{tabular}{|c|c|c|}
\hline Variable & Consented $(n=531)$ & $\%$ \\
\hline Age (years) & 70.1 (SD: 11.6) & \\
\hline$<40$ & 11 & 2.1 \\
\hline $40-49$ & 16 & 3.0 \\
\hline $50-59$ & 61 & 11.5 \\
\hline $60-69$ & 132 & 24.9 \\
\hline $70-79$ & 194 & 36.5 \\
\hline $80-89$ & 110 & 20.7 \\
\hline $90-99$ & 7 & 1.3 \\
\hline \multicolumn{3}{|l|}{ Gender } \\
\hline Female & 112 & 21.1 \\
\hline Male & 419 & 78.9 \\
\hline \multicolumn{3}{|l|}{ Ethnicity } \\
\hline British (White) & 302 & 56.9 \\
\hline Any other White background & 28 & 5.3 \\
\hline Mixed background & 1 & 0.2 \\
\hline Asian background & 8 & 1.5 \\
\hline Caribbean, African or Any other Black background & 9 & 1.7 \\
\hline Any other Ethnic Group & 5 & 0.9 \\
\hline Not Stated or Not Known & 178 & 22.3 \\
\hline \multicolumn{3}{|l|}{ Socioeconomic Status } \\
\hline Low & 419 & 80.58 \\
\hline Middle & 17 & 3.27 \\
\hline High & 69 & 13.27 \\
\hline Missing & 15 & 2.88 \\
\hline \multicolumn{3}{|l|}{ Trial } \\
\hline Yes & 32 & 6.0 \\
\hline No & 499 & 94.0 \\
\hline \multicolumn{3}{|l|}{ Comorbidities } \\
\hline Mean number of comorbidities & 3.02 (SD:1.82) & \\
\hline Hypertension & 198 & 37.3 \\
\hline Diabetes & 89 & 16.8 \\
\hline Other cancer & 82 & 15.4 \\
\hline Hypercholesterolaemia & 80 & 15.1 \\
\hline Respiratory disease & 62 & 11.7 \\
\hline Cardiovascular disease & 62 & 11.7 \\
\hline Chronic Kidney Disease & 32 & 6.0 \\
\hline Psychiatric Disorder & 23 & 4.3 \\
\hline \multicolumn{3}{|l|}{ Smoking } \\
\hline Yes & 183 & 34.5 \\
\hline No & 33 & 6.2 \\
\hline Unknown & 315 & 59.3 \\
\hline
\end{tabular}


Table 2 Clinical information (diagnosis and pathological) of KHP Bladder Cancer Biobank from April 2017-June 2019

\begin{tabular}{ll}
\hline Clinical variable & Con \\
\hline Diagnosis & 342 \\
New & 1899 \\
Recurrence & \\
Histology & 308 \\
Urothelial Cell Carcinoma & 165 \\
Papillary Urothelial Cell Carcinoma & 17 \\
Squamous Cell Carcinoma & 7 \\
Adenocarcinoma & 7 \\
Micropapillary variant & 3 \\
Plasmacytoid variant & 4 \\
Paraganglioma & 1 \\
Papilloma & 3 \\
Small cell carcinoma & \\
Sarcomatoid & 2 \\
Unknown &
\end{tabular}

Consented $(n=531)$

Grade

G1

$T$ stage

M stage

\section{Lymphovascular invasion}

TURBT

No

Surgery

Yes 
Table 2 Clinical information (diagnosis and pathological) of KHP Bladder Cancer Biobank from April $2017-J u n e ~ 2019$ (Continued)

\begin{tabular}{|c|c|c|}
\hline Clinical variable & Consented $(n=531)$ & $\%$ \\
\hline Neoadjuvant & 37 & 7.0 \\
\hline Adjuvant & 30 & 5.6 \\
\hline Chemotherapy & 20 & 3.8 \\
\hline Palliative & 6 & 1.1 \\
\hline Neoadjuvant and adjuvant & 2 & 0.4 \\
\hline None & 436 & 82.1 \\
\hline \multicolumn{3}{|l|}{ Radiotherapy } \\
\hline Yes & 47 & 8.9 \\
\hline No & 484 & 91.1 \\
\hline Intravesical Therapy & & 0.0 \\
\hline Yes & 180 & 33.9 \\
\hline Di Stasi & 76 & 14,3 \\
\hline $\mathrm{BCG}$ & 62 & 11.7 \\
\hline Mitomycin & 33 & 6.2 \\
\hline BCG and mitomycin in different occasions & 7 & 1.3 \\
\hline Di Stasi and mitomycin in different occasions & 1 & 0.2 \\
\hline Other & 1 & 0.2 \\
\hline No & 351 & 66.1 \\
\hline \multicolumn{3}{|l|}{ Intravesical Therapy Failure } \\
\hline Yes & 35 & 6.6 \\
\hline Poorly tolerated & 10 & 1.9 \\
\hline No & 6 & 1.1 \\
\hline Unknown & 129 & 24.3 \\
\hline Not applicable & 351 & 66.1 \\
\hline \multicolumn{3}{|l|}{ Laser ablation } \\
\hline Yes & 9 & 1.7 \\
\hline No & 522 & 98.3 \\
\hline \multicolumn{3}{|l|}{ Immunotherapy } \\
\hline Yes & 17 & 3.2 \\
\hline No & 514 & 96.8 \\
\hline
\end{tabular}

\section{Data repository}

All the data obtained has been collected from either GSTT Electronic Patient Records or Cancer Information System, contributing to the demographic (Table 1) and clinical (Table 2) database of the Biobank.

An overview of demographic and clinic-pathological data collected for the Biobank (Table 3) is outlined below in more detail.

\section{Demographics}

Demographic information includes age, gender, ethnicity and postcode (Table 1). Currently, the cohort comprises of 62.1\% White, 1.5\% Asian, 1.7\% Black, 1.1\% Mixed or other ethnic groups. The ethnic background of 178 patients (33.5\%) is not stated or not known. Postcode provides an opportunity to obtain information about the social deprivation index of the patients. We observed similarities in socioeconomic status (SES) between those who gave consent to the biobank and the GSTT total bladder cancer population $(80.6 \%$ of low socioeconomic status in the consented population vs $82.6 \%$ in the total population).

In addition, baseline information of the biobanked patients also provides data on comorbidities and smoking history [6], as the latter is a known risk factor for bladder cancer (Table 2).

Finally, in the demographic database we also collect data about trial participation. Of the 531 patients in the biobank, $32(6 \%)$ are currently also enrolled in a clinical trial.

\section{Clinical information}

Diagnostic information includes whether the bladder cancer diagnosis was new or recurrent, tumour 
Table 3 Overview of demographic and clinical information collected

\begin{tabular}{|c|c|c|}
\hline \multirow[t]{4}{*}{ Basics } & Sample size & 997 \\
\hline & Patients consented & 531 \\
\hline & $\begin{array}{l}\text { Number of } \\
\text { variables }\end{array}$ & 21 \\
\hline & $\begin{array}{l}\text { Involvement in } \\
\text { clinical trial }\end{array}$ & Yes, No \\
\hline \multirow[t]{6}{*}{ Demographics } & Age & \\
\hline & Gender & Male, Female \\
\hline & Ethnicity & \\
\hline & $\begin{array}{l}\text { Inclusion in } \\
\text { Clinical Trial }\end{array}$ & Yes, No \\
\hline & Comorbidities & $\begin{array}{l}\text { Hypertension, Diabetes, Other cancer, Hypercholesterolaemia, Respiratory disease, Cardiovascular disease, } \\
\text { Chronic Kidney Disease, Psychiatric Disorder }\end{array}$ \\
\hline & Smoking & Yes, No, Unknown \\
\hline \multirow{13}{*}{$\begin{array}{l}\text { Bladder cancer } \\
\text { characteristics }\end{array}$} & Diagnosis & New, Recurrent \\
\hline & Histology & $\begin{array}{l}\text { Urothelial Cell Carcinoma, Papillary Urothelial Cell Carcinoma, Squamous Cell Carcinoma, Adenocarcinoma, } \\
\text { Micropapillary variant, Plasmacytoid variant, Paraganglioma, Papilloma, Small cell carcinoma, Sarcomatoid, } \\
\text { Unknown }\end{array}$ \\
\hline & Grade & $\mathrm{G} 1, \mathrm{G} 2, \mathrm{G} 3$ \\
\hline & TNM stage & \\
\hline & $\begin{array}{l}\text { Lymphovascular } \\
\text { invasion }\end{array}$ & Yes, No \\
\hline & TURBT & Yes, No \\
\hline & Surgery & $\begin{array}{l}\text { Cystoprostatectomy, Cystectomy, Nephrouretectomy, Uretectomy, Nephrouretectomy and } \\
\text { cystoprostatectomy, Cystectomy and ureterectomy, Diverticulectomy, Nephrouretectomy and cystectomy, } \\
\text { Nephrouretectomy and partial cystectomy, Ureterostomy, Urethrectomy, Exenteration, None }\end{array}$ \\
\hline & Chemotherapy & Neoadjuvant, Adjuvant, Chemotherapy, Palliative, Neoadjuvant and adjuvant, None \\
\hline & Radiotherapy & Yes, No \\
\hline & $\begin{array}{l}\text { Intravesical } \\
\text { therapy }\end{array}$ & $\begin{array}{l}\text { Di Stasi, BCG, Mitomycin, BCG and mitomycin in different occasions, Di Stasi and mitomycin in different } \\
\text { occasions, Other, None }\end{array}$ \\
\hline & $\begin{array}{l}\text { Intravesical } \\
\text { therapy failure }\end{array}$ & Yes, No \\
\hline & Laser ablation & Yes, No \\
\hline & Immunotherapy & Yes, Poorly tolerated, Unknown, No, Not Applicable \\
\hline
\end{tabular}

histology, Grade, TNM staging and lymphovascular invasion (Table 2). A total of $35.6 \%$ patients in the biobank had a recurrent disease. In terms of histology, $89.1 \%$ patients had urothelial cell carcinoma, of which $31 \%$ were papillary urothelial cell carcinoma. Further details can be found in Table 2 and, as described above, the biobank population is representative of total bladder cancer population.

In addition to diagnostic information, the Bladder Cancer Biobank also contains treatment data that can be linked to samples (Table 2). For instance, $49.2 \%$ of patients had undergone a radical cystectomy.

\section{Utility and discussion}

The biobank provides a valuable resource for research. As an example, we have outlined one of the ongoing studies below.

\section{Phenotyping $\gamma \delta T$ cells in bladder cancer- results from a pilot study}

A recent analysis of over 18,000 tumour transcriptomes found a $\gamma \delta$ T cell transcription signature to be strongly associated with a positive prognosis in human cancers [7]. $\gamma \delta \mathrm{T}$ cells have also been implicated in responses to Bacillus Calmette-Guerin (BCG) therapy of non-muscle invasive bladder cancer $[8,9]$. However, studies in muscle-invasive bladder cancer have been limited. This project, which was approved by the Bladder Biobank Access Committee, uses a grid culture method to expand and isolate lymphocytes from tumour and paratumoural tissue samples selected by the Biobank from fresh cystectomy specimens. Matched blood and urine samples from bladder cancer patients are also collected by research nursing staff and processed by the biobank which supplies cell suspensions for downstream 
phenotyping. The presence and phenotype of $\gamma \delta$ T cells in bladder cancer and their associations with clinical features and outcomes are currently being examined and preliminary data has already been presented [10].

An additional arm of the project examines matched urine and blood samples from patients undergoing Bacillus-Calmette Guerin therapy for non-muscle invasive bladder cancer and these samples are also processed through the Biobank. Thus far, results show a $\gamma \delta \mathrm{T}$ cell compartment in tumour and para-tumoural tissue with carcinoma in situ affecting $\gamma \delta \mathrm{T}$ cell representation in both areas. Para-tumoural tissue also shows a stage related relationship with an increased percentage of $\gamma \delta$ T cells in para-tumoural tissue surrounding higher stage tumours.

\section{Strengths and weakness}

The KHP Bladder Cancer Biobank is a novel and valuable resource. Its size and depth allow the linkage of biospecimens and clinical data across the patient treatment journey with multidisciplinary input from both oncology and urology specialties. As detailed, the biobank is largely representative of the overall bladder cancer population of South East London. Despite this, currently a large proportion of bladder cancer patients diagnosed or treated at Guy's Hospital are not consented to the biobank; however, this provides a further valuable opportunity to increase the sample size and tissue resources in the future. The Biobank is a resource to be utilised and can be accessed by any academic or commercial establishment who has a valid research question. Potential applicants are encouraged to apply through the KHP Cancer Biobank website.

\section{Conclusions}

The KHP Bladder Cancer Biobank has assembled a comprehensive data repository, which is demographically and clinically representative of the total bladder cancer population in the Guy's and St Thomas Trust catchment area. With a rich data and tissue repository, the Biobank is a valuable resource for future translational research.

\section{Abbreviations}

BC: Bladder Cancer; KHP: King's Health Partners; TWiC: Trials within cohort study; PBMC: Peripheral blood mononuclear cells; GSTT: Guy's and St Thomas' NHS Foundation Trust; SES: Socioeconomic Status; BCG: Bacillus Calmette-Guerin

\section{Acknowledgements}

The authors are grateful to all sample and data donors who participated in the KHP BCaBB Biobank.

\section{Authors' contributions}

Study design: PK, CM, CG, MVH. Statistical analysis and interpretation: PK, CM, MVH. Manuscript preparation: PK, CM, MJ, MVH. Critical review of manuscript: PK, CM, CG, MJ, DE, DJ, SR, SH, FC, HW, AH, MK, RN, RT, SM, JR, MVH. All authors read and approved the final manuscript.

\section{Funding}

This work was partly supported by the Dianne and Graham Roberts Charitable Foundation. The funder did not play any role in the study design, collection, analysis or interpretation of data, or in the drafting of this paper. For further information, please contact Charlotte Moss: charlotte.moss@kcl.ac.uk

\section{Availability of data and materials}

The KHP Bladder Cancer Biobank welcomes requests from academic and commercial collaborators who have a valid health research request. Initially, an Access application form is completed which is reviewed by a dedicated Access committee within King's Health Partners who approve or reject applications according to predefined criteria.. All requests are dealt within a timely manner, with a response received usually within 2 weeks. Once approved, relevant costings for the samples are drawn up and agreed with the collaborators. More information about the Biobank and application process can be found on: https://www.khpbiobank.co.uk/

\section{Ethics approval and consent to participate}

The KHP Cancer biobank meets the current laws and ethical guidelines associated with tissue collection and use for research. This includes having a Human Tissue Authority licence (reference 12121) and a favourable opinion from the East of England - Cambridge East Research Ethics Committee (REC Ref 18/EE/0025). No administrative permissions and/or licenses were acquired by our team to access the data used in our research.

\section{Consent for publication}

Not applicable.

\section{Competing interests}

Mieke Van Hemelrijck is a member of the editorial board for the BMC Cancer journal.

\section{Author details}

${ }^{1}$ Translational Oncology \& Urology Research (TOUR), School of Cancer and Pharmaceutical Sciences, King's College London, Guy's Hospital, 3rd Floor Bermondsey Wing, London SE1 9RT, UK. Department of Oncology, Guy's and St Thomas' NHS Foundation Trust, London, UK. ${ }^{3}$ King's Health Partners Cancer Biobank, School of Cancer and Pharmaceutical Sciences, King's College London, London, UK. `Department of Urology, Guy's and St Thomas' NHS Foundation Trust, London, UK.

Received: 5 May 2020 Accepted: 18 September 2020 Published online: 25 September 2020

\section{References}

1. Wong MCS, Fung FDH, Leung C, Cheung WWL, Goggins WB, Ng CF. The global epidemiology of bladder cancer: a joinpoint regression analysis of its incidence and mortality trends and projection. Sci Rep. 2018;8(1):1129.

2. Bessa A, Maclennan S, Enting D, Bryan R, Josephs D, Hughes S, et al. Consensus in bladder Cancer research priorities between patients and healthcare professionals using a four-stage modified Delphi method. Eur Urol. 2019;76(2):258-9.

3. London City Council. London government directory. 2016; Available at: http://directory.londoncouncils.gov.uk/. Accessed 10 Dec 2019.

4. Wylie H, Cahill F, Santaolalla A, Moss CL, Enting D, Amery S, et al. Graham Roberts study protocol: first 'trials within cohort study' for bladder cancer. BMJ Open. 2019;9(9):e029468.

5. King's College London. Biobank Regulation. 2019; Available at: https://www. khpbiobank.co.uk/. Accessed 18 Jan 2020.

6. Rink M, Crivelli JJ, Shariat SF, Chun FK, Messing EM, Soloway MS. Smoking and bladder Cancer: a systematic review of risk and outcomes. Eur Urol Focus. 2015;1(1):17-27.

7. Gentles AJ, Newman AM, Long Liu C, et al. The prognostic landscape of genes and infiltrating immune cells across human cancers HHS public access author manuscript. Nat Med. 2015;21(8):938-45. https://doi.org/10. 1038/nm.3909.

8. Honda S, Sakamoto Y, Fujime M, Kitagawa R. Immunohistochemical study of tumor-infiltrating lymphocytes before and after intravesical bacillus Calmette-Guerin treatment for superficial bladder cancer. Int J Urol. 1997; 4(1):68-73 http://ovidsp.ovid.com/ovidweb.cgi? T=JS\&PAGE=reference\&D= emed4\&NEWS=N\&AN=1997089461. 
9. Alexandroff A, Black J, Bollina P, James K. Differential production of gamma delta $T$ cells in the urine of bladder cancer patients receiving Bacillus

Calmette Guerin immunotherapy. Int J Oncol. 1997. https://doi.org/10.3892/ ijo.10.2.387.

10. Joseph M, Cahill F, Wylie H, Enting D, Van Hemelrijck M, Hayday A.

Phenotyping Gamma Delta T cells in bladder Cancer. Front Oncol. 2019.

\section{Publisher's Note}

Springer Nature remains neutral with regard to jurisdictional claims in published maps and institutional affiliations.

Ready to submit your research? Choose BMC and benefit from:

- fast, convenient online submission

- thorough peer review by experienced researchers in your field

- rapid publication on acceptance

- support for research data, including large and complex data types

- gold Open Access which fosters wider collaboration and increased citations

- maximum visibility for your research: over $100 \mathrm{M}$ website views per year

At BMC, research is always in progress.

Learn more biomedcentral.com/submissions 